\title{
Editorial for NZJER Special Edition
}

\section{CHRISTOPHER PEACE and JOANNE CRAWFORD*}

This Special Edition arose from discussions about the lack of journals where articles about occupational health and safety (OHS) practice can be published both nationally and internationally. And, more than that, open access journals, which are available to practitioners and academics in New Zealand and elsewhere to publish the results of applied research, are even fewer. We have a story to tell about the special characteristics of work in New Zealand.

As we started to write this Editorial (August 2021), there were two newspaper articles that served as reminders of why OHS academics and practitioners work to prevent harm to workers and others. One article reported the death of a person who had fallen from a height in a wholesale store. The other article reported the conviction of a company whose workers had been exposed to the risk of death however, the company was found not guilty of reckless behaviour.

An analysis of workplace deaths in the decade 2005-2014 (Lilley et al., 2020) showed a total of 955 workers were fatally injured by trauma. High fatality rates were found for Māori and older workers, while miners had the highest rate of fatality. In contrast, Butchard (2019) reported 750-900 workers die each year due to occupational disease, approximately nine times more than deaths due to trauma. Such statistics and research help to explain why the work of OHS practitioners and academics is important.

Work featured in this Special Edition by Craig Braun, Siobhan Brophy, Mohamed Jassim, Elaine Mills, Parul Dagar, Christopher Peace, Allister Rose, and Mia Wichman arose from a question in 2019 from a lawyer "What is a safe system of work?" Drawing on the limited literature, their article reports on an investigation across a range of business activities and includes New Zealand case law and common law cases from the UK to help provide a preliminary answer to this question, structured using the goal tree. Part of the Theory of Constraints, a goal tree defines components necessary for the evaluation of alternative solutions to problems; in this case, the goal tree was tested iteratively using a set of small-scale case studies.

This lawyer's question also led Peace and Priestley-King to provide an important preliminary analysis of 201 decisions in the New Zealand District Court, between the years 2015-2021. While the safe system of work project included a few cases in the District Court, more cases have been collated, and a preliminary analysis carried out showing that most prosecutions arose from trauma, with few due to occupational disease. However, most work-related deaths arise from occupational diseases, not trauma. The reasons for this disparity need to be further explored, as do the options for how to better promote occupational health. In particular, how can owners and managers (especially of small- and medium-sized enterprises) be helped, today, to prevent tomorrow's occupational diseases?

Part of the continuing problem with the high rates of work-related injuries, illnesses, and fatalities in New Zealand is poor or inadequate risk assessments. Parkin helps establish a wider research agenda for the need for reliability in risk assessment techniques by focusing on the concept of risk velocity. We often overlook the speed with which events can unfold, perhaps resulting in trauma or longer-term disease. Her work and future research will help practitioners better comply with the implied

\footnotetext{
*Victoria University of Wellington, New Zealand
} 
requirements of the Health and Safety at Work Act 2015, for reasonably practicable testing for a risk assessment to be carried out before workers are harmed (Peace, 2017).

Using a small number of interviews, Marlowe, Bin \& Akhtaruzzaman provide insights into the long-term effects of workplace bullying on health, wellbeing, and on the professional and personal lives of bully-victims in New Zealand. Despite the small number of interviewees, their research puts a human face on the consequences of workplace bullying and shows the need for OHS professionals and managers to take action to prevent such adverse effects on people.

Young workers represent 40 per cent of part-time workers, but often are overlooked, and associated with the second highest rate of Accident Compensation Corporation injury claims. Therefore, Manglicmot, Cotton, Chen and Crawford's exploratory study in this Special Edition is welcomed. The authors show that young workers are often temporary and have precarious work, resulting in their not receiving necessary training or other protection. Will this lead to future occupational disease statistics?

Changes in the way we work due to the Covid-19 pandemic are considered by Gorjifard and Crawford. While working from home was necessary to ensure business continuity during Level 4, this has increased interest in a hybrid approach to work, with people working in both home and office environments. This paper examines some of the issues around OHS and challenges in maintaining a separation between work and home.

We thank the New Zealand Journal of Employment Relations for the invitation to edit this Special Edition, which was timed to be published with the Health and Safety Association New Zealand Conference 2021, rescheduled for March 2022 (due to ongoing Covid-19 restrictions in New Zealand), and hope it leads to further work that contributes to a reduction in workplace deaths, injuries and illness as well as improvements in worker wellbeing.

\section{References}

Lilley, R., Maclennan, B., McNoe, B. M., Davie, G., Horsburgh, S., \& Driscoll, T. (2020). Decade of fatal injuries in workers in New Zealand: insights from a comprehensive national observational study. Injury Prevention, 27(2), 1-7. https://doi.org/10.1136/injuryprev-2020-043643

Peace, C. (2017). The reasonably practicable test and work health and safety-related risk assessments. New Zealand Journal of Employment Relations, 42(2), 61-78.

WorkSafe. (2021). Work-related health estimates and burden of harm. https://www.worksafe.govt.nz/topic-and-industry/work-related-health/work-related-healthestimates-and-burden-of-harm 